\title{
Comparative Methodology and Pluralism in Legal Comparison in a Global Age
}

\author{
Roberto Scarciglia \\ Department of Political and Social Sciences, University of Trieste, Trieste, Italy \\ Email: scarcigliar@sp.units.it
}

Received 20 January 2015; accepted 2 March 2015; published 4 March 2015

Copyright (C) 2015 by author and Scientific Research Publishing Inc.

This work is licensed under the Creative Commons Attribution International License (CC BY). http://creativecommons.org/licenses/by/4.0/

c) (7) Open Access

\begin{abstract}
This article grew to look deeper into the relationship between different methodological tools in comparative law enquiries. There are several factors that currently affect these enquiries, such as the emergence of new spheres of normativity and transnational actors determining a new configuration of the relationship between centre and periphery. Different forms and visions of legal pluralism could characterise a cultural tradition and different ways, in which existing nations, which have a pluralistic legal system, interact. Furthermore, one might add the consideration that the presence of different forms of pluralism-a pluralism of pluralisms-implies a constant and urgent need to reconsider the adequacy of the methodologies in comparative law. Hence, we can use different approaches because there are different purposes that the comparison pursues. Though the horizontal comparison is certainly a widespread tendency for comparative analyses, from a methodological point of view, we need to consider the importance of forms of vertical comparison, both a top-down and bottom-up approach.
\end{abstract}

Keywords

Comparative Methodology, Pluralism, Globalization

\section{Introduction}

At the beginning of a comparative enquiry, one of the main tasks for a researcher is the choice of methodologies. Friedrich Nietzsche, in his The Dawn of a Day, 1911 (Nietzsche, 1911), emphasised the concept according to which "There is no exclusive method of knowing in science. We must deal with things tentatively, treating them by turns harshly or justly, passionately or coldly. One investigator deals with things like a policeman, another like a confessor, and yet a third like an inquisitive traveller". The relevance of Nietzsche's words and their dynamic nature requires a legal scholar with comparative interests asking questions on methodology. He must take 
into account the complexity of legal phenomena and the methodological tools also coming from other sciences (i.e. anthropology, sociology, political science, and neuroscience). Consequently, the debate regarding the suitability of different methods has many and varied facets. It mainly depends on the legal tradition to which the scholar belongs, his/her legal education, the impact of the religious factors on his/her way of interpreting a transnational source of law. From this point of view, it is not surprising that there might be a sliding scale of methods while taking account of the central role played by the functional method for legal comparison.

The aim of this paper is to show how the methodological tools used in comparative analyses are not completely suitable to study complex phenomena, and it is necessary to consider the integration of horizontal and vertical methodologies in legal comparison. There are several factors that currently affect these enquiries, such as the emergence of new spheres of normativity and transnational actors determining a new configuration of the relationship between centre and periphery. Furthermore, one might add the consideration that the presence of different forms of pluralism - a pluralism of pluralisms-implies a constant and urgent need to reconsider the adequacy of the methodologies in comparative law. In this regard, we believe that comparative law can play a crucial role in a global world.

We shall start this reflection by the knowledge of our object of study, constructing a reading of materials (Frankemberg, 2006). Since the first approach, a comparative lawyer is alone (Merryman, 1999). He lives with "his epistemological prejudices, his attitude towards the absurd consequences of the theories that he accepts" (Feyerabend, 1978; Adams \& Griffiths, 2012). According to Palmer, "method is now identified by the "techniques' by which comparisons are carried out. These techniques have thereby acquired the status of separate methods: thus we have historical, functional, evolutionary, structural, thematic, empirical and statistical comparisons, and all of these can be carried out from a micro or macro point of view." Choosing a method is undoubtedly difficult (Palmer, 2005; Reimann, 2004). Annelise Riles brings out that a comparatist engages in comparison with the purpose "to find a model for modernization or to harmonize legal regimes" (Riles, 2001).

Therefore, a comparatist needs to know the core of the methodological propositions and be in contact with other scholars also belonging to other epistemic communities. He bears in mind that this knowledge can have a significant impact on the results of his research (Gerber, 2011). Leaving aside other mundane objectives, frequently characterized by decorative results—and, consequently, not very functional-a researcher knows that these results "reveal the skills, methods and talents of their markers; they allow us to distinguish the good, the bad and the temporary in means of production. A thing well-made will last [ $\cdots]$ ]" (Glenn, 2010). From this point of view, we regard similarities, between two or more legal systems, as coincidences or dissonances reveal the features of "cultural postures" of other legal systems. However, both perspectives can be helpful for a comparatist to simplify the study of foreign law. On one hand, it is, therefore, important to make into account the macrocomparative studies, with the aim of identifying factors and variables that influence the transformation of legal systems (Zumbansen, 2012). Developments in technology have enabled rapid progress to facilitate this knowledge. On the other hand, the knowledge of the language and the cultural and social factors characterising a legal system may allow revealing, "An experience without theory is just as incomprehensible as is (allegedly) a theory without experience". "Eliminate part of the theoretical knowledge of a sensing subject and you have a person who is completely disoriented and incapable of carrying out the simplest action." None of these factors can be separated from the passion which "gives rise to specific behaviour which in turn creates the circumstances and the ideas necessary for analysing and explaining the process, for making it 'rational'” (Feyerabend, 1978).

The structure of this article is simple. After a concise introduction to the methodological tools for studying complex phenomena (1), I discuss the concept of pluralistic methodology (2) and the choice of developing vertical methodology for comparative law (3).

\section{Methodological Pluralism and Legal Comparison}

From an epistemological point of view, the introductory questions can certainly be useful for a reflection on comparative methodology. A comparatist always searches for the best solution analyzing legal problems interrelated with religious pluralism. It "is an exercise that is no doubt valuable, but it is not really any more comparative in its methodological sophistication than legal reasoning in general" (Samuel, 2011). Feyerabend has rightly noted that "who wishes to maximize the empirical contents of the view he holds and who wants to understand them as clearly as he possibly can must therefore introduce other views; that is, he must adopt a pluralistic methodology" (Feyerabend, 1978). The first element, which we can here take into account, concerns the 
spread of tools that enable us to learn faster about "other" cultures and the relations between different legal and cultural traditions. In the ancient world, this circulation of information or models probably had no formal methodology; we can found it in the common chthonic origins, which would still have had culture-specific characteristics.

The progressive development of other forms of communication and the collection of information on the World Wide Web today reach and transform the comparatists. They are no longer the travellers described by Tocqueville, but could become "virtual comparatists" and acquire sources of inspiration and information from the Web. How and with what results? Moreover, to what extent are there language barriers? On the Web, there is not a global language, but many. On the one hand, the growing wealth of available materials is a valuable aid to set up a comparative research, including a diachronic point of view. On the other hand-according to McLuhan-, this implementation means, “'the message’ of any medium or technology is the change of scale or pace or pattern that it introduces into human affairs. Earlier, the railway did not introduce movement or transportation or wheel or road into human society, but it accelerated and enlarged the scale of previous human functions, creating totally new kinds of cities and new kinds of work or leisure” (McLuhan, 1994). This view undoubtedly expresses the need to study different legal systems, rather than just what belongs to the legal and cultural traditions of civil law or common law. One could observe that a type of law requires X method; B law requires Y method and $\mathrm{C}$ law requires $\mathrm{Z}$ method. According to Husa, "this kind of methodological mentality does not take into account legal pluralism in the true sense” (Husa, 2011).

By "legal pluralism” Griffiths refers to "the presence of a social field of more than one legal order" (Griffiths, 1986). Different forms and visions of legal pluralism could characterise a cultural tradition and different ways in which existing nations with a pluralistic legal system. For instance, some countries could accept that ethnic or religious communities may operate their rule systems with official legal effects on family law. "Marriage, divorce inheritance and other matters dealing with personal status may be regulated by the rules of that particular community on the basis of the sanction of the state” (Edge, 2013). However, they may also be oblivious of, or consciously seek to counteract state sanction. In the United Kingdom, e.g. "Muslims are relating to something more than the norms of the English legal system alone. Issues then arise over how the different systems of norms interact and might coexist.” From this point of view, we could have at least two forms of legal pluralism: "where, within a state, enclaves with separate legal rules may operate; and legal systems which sanction or enforce different systems of legal rules in state-wide but separate and parallel court systems” (Edge, 2013). The coexistence of different sources of law represents a significant problem for the lawyer accustomed to the principle of hierarchy coined within the constitutional law of national states. This problem does not only concern the issue of legal pluralism, but also that of globalization that can create uniformity in some places and integration in others (Riles, 2006). Legal rules such as, e.g. statutes, acts, cases, customs can coexist and circulate in the global arena. It is normal to wonder what happens in cases of collision between different norms that the courts could apply to the case at hand. It is evident that a key element, in such debates and processes, is the power to determine what the law is and what is not, or what is legal and what something else is. All these processes of globalization or regionalization—such as the process of Europeanisation- “are challenging the mechanical understanding of methodology” (Husa, 2011), as well as the coercive and unifying roles of legal centralism. By the way, if the role of the state is necessary to allow the entry of rules coming from other geographical areas, there are mechanisms by which the opposite could happen. For example, the rules and norms of Muslim communities in England could form a new system of law (called angrezishari'at) (Menski, 2014). Muslims living in the UK transmit the requirements of English law into the Islamic law.

The creation of a system of sources not deriving from legal centralism is the product of conceptions that consider legal pluralism as a fact. From this last point of view, "what are the consequences for the methodology of legal research [...]? And, if there is no legal centralism, but pluralism what method(s) should one deploy? (Husa, 2011). This question clearly relates to the methodology of comparative law. It is difficult, for example, to imagine a comparative analysis of the sources of law in a global space crossing the borders of states, without an appropriate methodological choice. According to Adams and Griffiths, "there is no single comparative method because there is no single question” if you compare domestic and foreign law. The method will mostly vary, from formalism ("law in the books") through legal realism ("law in practice") to various sorts of functional comparison (Adams \& Griffiths, 2012). Furthermore, the presence of different forms of pluralism-a pluralism of pluralisms - implies a constant and urgent need to reconsider the adequacy of the methodological tools have been used up to now by comparative lawyers. 


\section{Globalization, Legal Pluralism and Vertical Comparison}

The opinion of some comparative lawyers on legal pluralism has led to the conclusion that "legal pluralism is a limited, exceptional and disappearing phenomenon" (Griffiths, 1986). According to Michaels, "the irreducible plurality of legal orders in the world, the coexistence of domestic state law with other legal orders, the absence of a hierarchically superior position transcending the differences, all of these topics of legal pluralism reappear on the global sphere” (Michaels, 2009). All legal systems, Western or non-Western, are plural and then it is necessary to consider legal pluralism as a global phenomenon. Why are comparative law and its methodologies useful, with respect to different forms of pluralism? From a global point of view, there are new factors in comparative studies, such as the emergence of new spheres of normativity, private powers and transnational actors in an international arena, a new configuration of political relations, and a criticism of the Western view of the relationship between centre and periphery. To this element_-defined "impact" or "enmeshment between the global and the local”, it is necessary to add those of extensity, intensity and velocity, as traits of globalisation (Michaels, 2013), opening up new frontiers in comparative law scholarship (Auby, 2010).

The processes of globalisation are something more than the simple expansion of Western influence that comes across local and particular forms of resistance. We cannot simplify the complexity of this phenomenon into a dichotomous opposition. As Glenn notes, "each tradition, or at least each of the major ones, has within it the potential to globalize, to be used for purposes of domination in a way which suppresses, by manifold means, variant opinion" (Glenn, 2010). With reference to the three main actors of globalisation-the West, Islam and East Asia, it is not possible to predict the development of this competition. However, might one believe that comparative law can help in the creation of a common ground, a common zone of impact; an intersection set where to address the comparative analysis? In which set do different actors play their roles by using different procedures?

In order to outline new directions in comparative law, we could say that legal comparison is mainly horizontal. Legal scholars are used to compare legal systems or institutions belonging to the same level, both national (e.g. for comparative constitutional law) and international level (e.g. comparing international institutions) (Momirov \& Naudé Fourie, 2009). Many of these scholars are today devoted to the study of global law, highlighting the need to use the comparative method, and this does not necessarily mean that they have to consider only a horizontal form of legal comparison. This way could ignore the existence of legal transplants, as well as a development of principles and rights in a global space. An imposition of global rules at the national level or the adoption in a global sphere of principles and values of a domestic legal system oblige legal scholars to rethink the use of comparative methodology.

However, we can shift our focus from horizontal to vertical methodology in comparative law. For "vertical comparison", I mean not only the analysis of successive forms of the same legal system, but also the comparison between systems, or legal institutions, do not belong to the same level. We will talk about this second perspective. From this point of view, comparative methodology can be vertical top-down or bottom-up. In the first case, we can use this mode of legal comparison "e.g. typically in the context of the internalization of international norms and regulations by national legal orders, whereby national law is required to incorporate international concepts into the national legal system” (Momirov \& Naudé Fourie, 2009). In the second case, we can use vertical, bottom-up, legal comparison, analyzing "the transposition of legal concepts, or the ideas behind them, from national to international level” (Momirov \& Naudé Fourie, 2009). For example, in constitutional law, the comparison is horizontal when one might take into account national legal systems (or their legal formants) or even national systems in relationship with supranational legal systems. In terms of vertical comparison, there is a further approach used in cases in which international standards incorporate national principles (Rosenblum, 2007; Chodosh, 1999).

Some analytical studies on vertical comparative methodology are in the field of administrative law. A starting point for analysing this issue could be the paper by Felix Frankfurter, published in 1927 in the University of Pennsylvania Law Review, and entitled “The Task of Administrative Law”. When analysing the relationship between judicial review and administrative law, he notes that: "therefore, a subject like "judicial review", in any scientific development of administrative law, must be studied not only horizontally, but vertically, e.g., "judicial review” of Federal Commission orders, “judicial review” of postal fraud orders, “judicial review” of deportation warrants. For judicial review in postal cases, for instance, is coloured by the whole structure of which it forms a part, just as in land office cases, or in immigration causes or in utility valuations or in insurance license revoca- 
tions, it derives significance from the nature of the subject matter under review as well as from the agency which is reviewed" (Frankfurter, 1926).

However, in the comparative process one might have to use different methodologies according to the function that one intends to carry through the comparison. The methods of comparative law have developed over time and comparatists are always in search of something new (Chodosh, 1999). This is also justified by the fact that there are different categories of people who make use of comparative law: scholars or academic comparatists, legislative or reform comparatists and law-applying comparatists (Palmer, 2005). They can use different methodologies because there are different purposes that the comparison pursues. Although the horizontal comparison is certainly more widespread, we will only consider forms of vertical comparison and, in particular, a top-down and a bottom-up approach. The former regards the mobility of legal concepts from national to international levels and vice-versa.

The reasons, we rethink the use of the comparative methodology, and, particularly, developing a cross-echelon comparison, are different. We will shortly describe two.

First, before the 90s, we use legal comparison and transpositions of legal concepts, from one legal system into another, by "horizontal” methodology. However, in the following years, transnational interactions, global commerce, a rapid development of web communication, such as the global economic crisis, have led to greatercomplexity in the analysis of legal phenomena. Consequently, this complexity had impact on the way to make legal comparison and circulation and integration of legal rules and models. In this regard, Gutteridge noted that "any relationship or kinship between comparative law and the law of nations must, therefore, be of a shadowy nature, and the only possible link between the two disciplines is to be found in the extent to which the comparative study of private law can be regarded as an instrument to be employed in promoting the growth and development of the law of nations" (Gutteridge, 1946). We could consider that "the integration rules can present a high degree of complexity, mainly from the institution of new procedures that allow producing these rules. In any case, it does not propose changes on the closing of the system” (Pfersmann, 2001). This setting of the problem does not however help to analyze all those cases in which the mobility and the transplantation of legal concepts occur in different forms, and sometimes in a tacit form.

Second, vertical comparison could contribute to the development of a common zone of impact. By "impact"-or "enmeshment between the global and the local"-we mean that "local events can have global consequences, and that on the other hand global developments materialize locally” (Michaels, 2013). The concept of intersection of sets can help clarify this. Let us take into consideration two sets: e.g. two actors in a global arena, denoted A and B. For example, we consider Germany (state actor) (A) and World Bank (non-state actor) (B), e.g., with different economic procedural rules: those of country $A\left\{r, r_{1}, r_{2}, \cdots, r_{n}\right\}$ (which belong to set $A$ ), and those of institution $B\left\{x, x_{1}, x_{2}, \cdots, x_{n}\right\}$ (which belong to set B). Suppose that “a) $r, r_{1}, r_{2}, \cdots, r_{n} \in A$; b) $r, r_{1}, r_{2}, \cdots$, $r_{n} \notin B$; c) $x, x_{1}, x_{2}, \cdots, x_{n} \in \sigma B$; d) $x, x_{1}, x_{2}, \cdots, x_{n} \notin A ”$. It is possible to identify one or more element in the two sets (e.g., a rule, a procedure, or a legal formant, common to both sets), which could form part of an intersection between the two sets $(I=A \cap B)$, and may contain other elements common to A and $B$. We can see this concept by Venn diagrams that enable the students to see the relationships between two or three sets. They can then identify similarities and differences.

The intersection of different sets graphically could represent a common zone of impact in a global space. From this point of view, bottom-up comparative law method-but the same we say for top-down-could be necessary for developing this set. In this case, according to Gerber, we can show that "a comparative approach grounded in functionalism only tends to focus on the substantive aspects of law, while new comparative objectives also require an emphasis on e.g. procedural elements (Gerber, 1998)” and flexibility to construct a conceptual model.

\section{Concluding Remarks}

This short article follows the idea, perceived by many legal scholars that legal pluralism and the effects of globalization have required a different approach with the comparative methodology. According to Husa, "if there is no legal centralism but pluralism what method(s) should one deploy?” (Husa, 2011). Comparison needs a plurality of lenses and more and more new focuses, which can combine the dynamic profiles of legal traditions with the transition from the traditional study of nation-states to that of epistemic communities. These communities can be characterised by people belonging to different cultural and normative traditions. However, it is possible 
to find elements in common, which tie together these traditions and represent, on one hand, a common heritage of values and, on the other hand, their differences. The fact is that through a functional approach - or a neofunctional perspective-it seems possible to identify these common elements even if belonging to different legal traditions: a common ground of traditions. In particular, this paper wants to indicate, however briefly, that the methodological tools used in comparative analyses are not completely suitable to study complex phenomena. We need to consider the integration between horizontal and vertical methodologies in legal comparison, and, above all, that many legal scholars compared legal systems or institutions belonging to the same level, both national (e.g. for comparative constitutional law) and international level. For "vertical comparison", I mean not only the analysis of successive forms of the same legal system, but also the comparison between systems, or legal institutions, do not belong to the same level. This mode of comparison can be vertical top-down or bottom-up.

Vertical comparative methodology could have an impact on comparative process. Momirov and Naudé Fourie divide it in four stages: a) formulation of hypothesis based on observation of prima facie similarities; b) construction and verification of conceptual model-tertiumcomparationis for vertical comparison-through horizontal comparison; c) conduction of vertical comparison (similarities and differences); d) synthesis (hypothesis proved/disproved, conclusions) (Momirov \& Naudé Fourie, 2009).

By way of summary, we indicate that vertical comparison could contribute to the development of a common zone of impact. It means that local events could have global consequences, and vice-versa. Two different legal orders, analysed from a horizontal or vertical point of view, appear as a binary order, in which differences coexist with a set of common principles. A peaceful coexistence should substantially exclude the rigid positions of legal centralism and the idea of a state monopoly of the production of valid norms. However, a comparatist should get used to consider that legal mind should be more multivalent than bivalent, beyond a binary opposition. Although the constitutions contain the principle of the hierarchy of sources of law and the mechanisms for resolving conflicts between legal norms, it may happen that a regional or global rule could interfere with these predictions. From a comparative law point of view, the fields, in which this conflict can happen theoretically, are many. Constitutional values, jurisdiction, family law, criminal law, and public space of individual religious freedom, are fields of application of a cross-echelon mode of comparison. This does not exclude, however, that one or more legal systems may not contain (or only marginally contain) common elements: sets have different characteristics, as opposed to the well-known classification schemes. If one imagines multiplying sets by transferring it to a black and white image, the negative could become a difference map in which the law in dissociation from the state could be visible.

According to Husa with reference to a normative pluralism, "polynomia necessarily means competence between various norms-producers: national, international, European, transnational, local regional, indigenous, business-based and so on. To write "method" with a lower case and to reject legal centralism leads doing the same to legislator(s) even while some of the ramifications may be harmful from the point of view of democracy as it has been understood in western constitutional law (Husa, 2011)". Reflecting on global justice, Garcia introduces the concept of "Global Basic Package", containing a set of political, social and economic rights, guaranteed by a global law. Global institutions, supranational actors and national states, both public and private institutions, would give life to this common zone of impact (Garcia, 2013). However, in the absence of significant changes of methodology, comparative law is not fully able to cope with the impact of globalisation on local legal traditions and develop a common global heritage.

To conclude, it is crucial to see that methodology, or methodologies, in comparative law, can help us to locate this middle ground, "a place: between cultures and peoples, between empires and the world of villages withoutstate, [...] where different peoples recompose their differences" (White, 1991; Melissaris, 2009). A comparative analysis, which takes place in this direction, highlights more and more cosmopolitan character, as well as the need to test the validity of the methods of comparative law in action within a global point of view.

\section{References}

Adams, M., \& Griffiths, J. (2012). Against “Comparative Method”: Explaining Similarities and Differences. In M. Adams, \& J. Bomhoff (Eds.), Practice and Theory in Comparative Law (p. 279). Cambridge: Cambridge University Press.

Auby, J.-B. (2010). La globalization, le droit et l'Etat. Montchrestien: LGDJ.

Chodosh, H. E. (1999). Comparing Comparisons: In Search of Methodology. Iowa Law Review, 1038. 
Edge, J. (2013). Islamic Finance, Alternative Dispute Resolution and Family Law: Developments towards Legal Pluralism? In R. Griffith-Jones (Ed.), Islam and English Law. Rights, Responsibilities and the Place of Shari'a (p. 138). Cambridge: Cambridge University Press.

Feyerabend, P. (1978 [1975]). Against Method: Outline of an Anarchistic Theory of Knowledge. Verso Edition: London.

Frankfurter, F. (1926). The Task of Administrative Law. University of Pennsylvania Law Review, 75, 620.

Garcia, F. J. (2013). Between Cosmopolis and Community: Globalization and the Emerging Basis for Global Justice. Boston College Law School Faculty Papers, 37-40.

Gerber, D. J. (2011). Method, Community and Comparative Law: An Encounter with Complexity Science. Roger Williams University Law Review, 16, 112.

Gerber, D. J. (1998). System Dynamics: Toward a Language of Comparative Law? American Journal of Comparative Law, 46, 719-737. http://dx.doi.org/10.2307/840989

Glenn, P. H. (2010 [2000]). Legal Traditions of the World: Sustainable Diversity in Law (4th ed., p. 7). Oxford: Oxford University Press.

Griffiths, J. (1986). What Is Legal Pluralism? Journal of Legal Pluralism and Unofficial Law, 18, 1-55. http://dx.doi.org/10.1080/07329113.1986.10756387

Gutteridge, H. C. (1946). An Introduction to the Comparative Method of Legal Study and Research (p. 61). Cambridge: Cambridge University Press.

Husa, J. (2011). The Method Is Dead, Long Live the Methods! European Polynomia and Pluralist Methodology. Legisprudence, 5, 249-271. http://dx.doi.org/10.5235/175214611799248913

McLuhan, M. (1994). Understanding Media: The Extensions of Man (p. 16). Cambridge, MA: MIT Press.

Melissaris, E. (2009). Ubiquitous Law (p. 4). Farnham: Ashgate.

Menski, W. (2014). Flying Kites in a Global Sky. In R. Scarciglia, \& W. Menski (Eds.), Islamic Symbols in European Courts (p. 13). Padova: Cedam.

Merryman, J. H. (1999). The Loneliness of the Comparative Lawyer and Other Essays in Foreign and Comparative Law. The Hague: Kluwer.

Michaels, R. (2009). Global Legal Pluralism. Annual Review of Law and Social Science, 5, 243-262. http://dx.doi.org/10.1146/annurev.lawsocsci.4.110707.172311

Michaels, R. (2013). Globalization and Law: Law beyond the State. In R. Banakar, \& M. Travers (Eds.), Law and Social Theory (2nd ed., p. 3). Oxford: Hart Publishing.

Momirov, A., \& Naudé Fourie, A. (2009). Vertical Comparative Law Methods: Tools for Conceptualizing the International Rule of Law. Erasmus Law Review, 2, 295.

Nietzsche, F. (1911). The Dawn of a Day (Eng. Transl.). New York: The MacMillan Company.

Palmer, V. V. (2005). From Lerotholi to Lando: Some Examples of Comparative Law Methodology. American Journal of Comparative Law, 53, 261-290.

Pfersmann, O. (2001). Le droit comparé comme interprétation et comme théorie du droit. Revue internationale de droit comparé, 53, 275-288. http://dx.doi.org/10.3406/ridc.2001.17976

Reimann, M. (2004). The Progress and Failure of Comparative Law. American Journal of Comparative Law, 50, 671.

Riles, A. (2001). Rethinking the Masters of Comparative Law. Oxford and Portland, OR: Hart.

Riles, A. (2006). Comparative Law and Socio-Legal Studies. In M. Reimann, \& R. Zimmermann (Eds.), The Oxford Handbook of Comparative Law (p. 775). Oxford: OUP.

Rosenblum, D. (2007). Internalizing Gender: Why International Law Theory Should Adopt Comparative Methods. Columbia Journal of Transnational Law, 45, 759.

Samuel, G. (2011). Does One Need an Understanding of Methodology in Law before One Can Understand Methodology in Comparative Law. In M. Van Hoecke (Ed.), Methodologies of Legal Research: Which Kind of Method Per What Kind of Discipline (p. 182). Oxford: Hart.

White, R. (1991). The Middle Ground: Indians, Empires, and Republics in the Great Lake Regions, 1650-1815. Cambridge: Cambridge University Press.

Zumbansen, P. (2012). Transnational Comparisons: Theory and Practice of Comparative Law as a Critique of Global Governance. Toronto: Osgoode Hall, Research Paper Series. 